\title{
Quasi-Z-Source Half-Bridge DC-DC Converter for Photovoltaic Applications
}

\author{
Dmitri Vinnikov, Andrii Chub, Oleksandr Husev \\ Department of Electrical Engineering \\ Tallinn University of Technology \\ Tallinn, Estonia \\ dmitri.vinnikov@ttu.ee
}

\begin{abstract}
This paper presents a novel quasi-Z-source halfbridge galvanically isolated DC-DC converter intended for the photovoltaic applications. The topology could be envisioned as an alternative to the boost half-bridge DC-DC converter but the benefit of its symmetric structure reduces the threat of transformer saturation due to the de flux. The proposed converter features the continuous input current and could be used either with one or two input voltage sources.
\end{abstract}

Keywords - impedance-source converters, DC-DC power converters, galvanic isolation, renewable energy sources

\section{INTRODUCTION}

The impedance-source (IS) galvanically isolated DC-DC converter was proposed in [1] as an alternative power conversion approach for the renewable energy applications, in particular, for PV power systems. In general, the new topology was derived from a classical voltage source full-bridge isolated DC-DC converter by adding a passive IS network (ISN) to its input terminals. The IS network is a two-port passive circuit that consists of capacitors, inductors and diodes in a special configuration. It could be short- or open-circuited without any damages of the main DC-DC converter. Therefore, the IS DC-DC converter combines the basic properties of the voltage source and current source converters, allowing both the buck and boost functions within the single switching stage. Thanks to this unique property, the IS galvanically isolated DC-DC converters are also known as converters for a wide input voltage and load regulation range.

According to the topology of the ISN, the existing IS DC-DC converters could be categorized as Z-Source [1, 2], quasi-Z-Source [3], Trans-Z-Source [4], Trans-quasi-Zsource [4], and Y-source based converters [5]. The quasi-ZSource (qZS) approach has gained its popularity fast in the

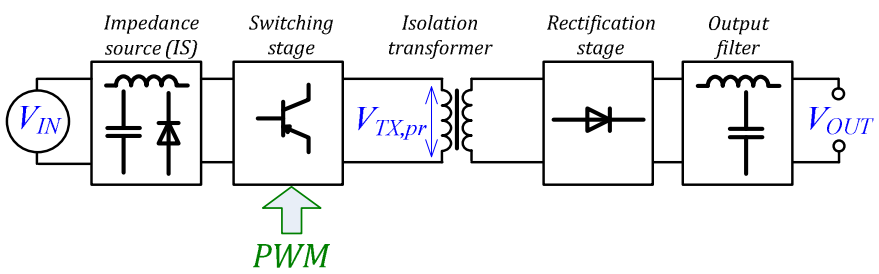

Fig. 1. Generalized block diagram of the impedance source galvanically isolated DC-DC converter.

\author{
Janis Zakis \\ Institute of Industrial Electronics and Electrical Engineering \\ Riga Technical University \\ Riga, Latvia \\ janis.zakis@,ieee.org
}

renewable energy applications since it features the continuous input current during the shoot-through operation mode and reduced component stresses.

In the switching stage realization, the dominant solution is the full-bridge inverter, which could be realized in a single- or three-phase configuration [3]. The IS DC-DC converter with the push-pull switching stage $[6,7]$ is characterized with the reduced number of transistors with performance close to the full-bridge counterpart. However, in this topology the transistors must block twice the dc link voltage, therefore their voltage stress is twice higher than in the full-bridge switching stage.

We propose the novel qZS half-bridge galvanically isolated DC-DC converter as an alternative approach to the IS DC-DC converters with a reduced number of switches. In contrast to the push-pull counterpart, it features twice reduced voltage stress of the transistors and a two-winding isolation transformer. The topology is positioned as a power conditioning unit for PV applications with single- or dualinput functionality.

\section{QZS HALF-BRIDGE DC-DC CONVERTER}

\section{A. Derivation and general description}

Fig. 2 shows the generalized power circuit layout of the proposed qZS half-bridge DC-DC converter. It is based on two identical qZS networks with a neutral node $n$ between the capacitors $C_{1}$ and $C_{3}$. Mirror connection of two qZS networks enables the symmetrical structure of the impedance source network. The topology could be used either with one or two input voltage sources. By help of the voltage doubler rectifier (VDR) the high voltage gain is realized with the optimal turns ratio of the isolation transformer $T X$.

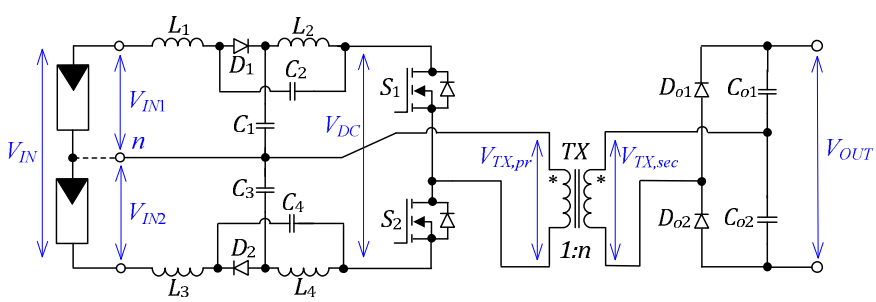

Fig. 2. Power circuit layout of the qZS half-bridge DC-DC converter. 
The output voltage of the converter is controlled by the variation of the shoot-through duty cycle of the inverter stage similarly to the qZS full-bridge DC-DC converter discussed in [8]. We examine here the topology with a single input voltage source $V_{I N}$, therefore the primary winding voltage of the isolation transformer can have three different levels: $B\left(V_{I N} / 2\right), 0$, and $+B\left(V_{I N} / 2\right)$, where $B$ is the boost factor of the inverter defined as $B=V_{D C} / V_{I N}$.

\section{B. Steady State Analysis}

Similarly to any other qZS based galvanically isolated DC-DC converter, the shoot-through states in our topology are generated by the cross-conduction of both switches of the inverter leg (Fig. 3). The switching period in the continuous conduction mode (CCM) consists of two shoot-through states (with a total duration $t_{S}$ ) and two active states (with a total duration $t_{A}$ ), and can be generally expressed as

$$
\frac{t_{A}}{T}+\frac{t_{S}}{T}=D_{A}+D_{S}=1,
$$

where $D_{A}$ is the duty cycle of the active states, $D_{S}$ is the duty cycle of the shoot-through states and $T$ is the switching period. The converter is controlled by the symmetrical pulse width modulation (PWM), therefore the active and shoot-through states within one switching period are evenly split into equal intervals of half the duration.

It is seen from Fig. 3 that the proposed topology has three main operating states in the CCM: shoot-through state, positive active state and negative active state.

Shoot-through state $\left[t_{0}<t<t_{1}\right.$ and $\left.t_{2}<t<t_{3}\right]$ : Shootthrough states are generated by the cross-conduction of $S_{l}$ and $S_{2}$. The shoot-through state is used to boost the magnetic

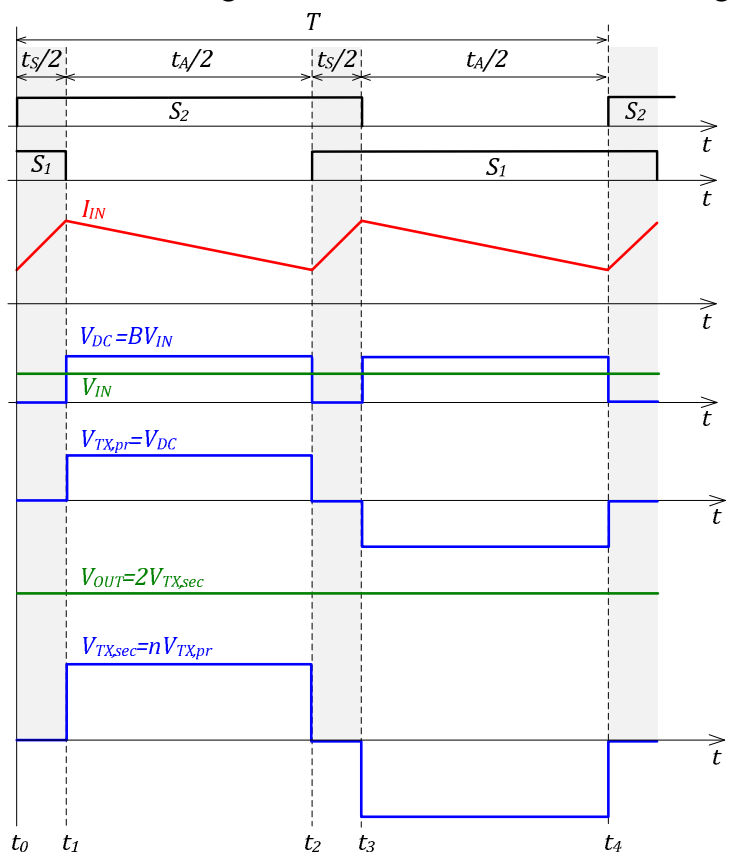

Fig. 3. Control principle and idealized operating waveforms of the proposed topology. energy stored in the qZS inductors $L_{1} \ldots L_{4}$ without shortcircuiting the capacitors $C_{1} \ldots C_{4}$. This increase in inductive energy, in turn, provides the boost of voltage seen on the transformer primary winding during the active states of the converter. The equivalent circuit of the converter in this state is presented in Fig. $4 a$. During this state the voltage across the isolation transformer is zero.

Positive active state $\left[t_{1}<t<t_{2}\right]$ : During this state, the switch $S_{2}$ is conducting, thus resulting in a positive voltage $V_{T X, p r}$ across the primary winding of the isolation transformer. The equivalent circuit of the converter in this state is presented in Fig. $4 b$. It is seen that only the bottom qZS network $\left(C_{3^{-}} C_{4^{-}}\right.$ $\left.D_{2}-L_{3}-L_{4}\right)$ maintains the power transfer to the output. At the same time, as the inductor $L_{2}$ is not involved in the power flow, it charges the capacitor $C_{2}$.

Negative active state $\left[t_{3}<t<t_{4}\right]$ : Switch $S_{1}$ is conducting, thus resulting in a negative voltage $V_{T X, p r}$ across the primary winding of the isolation transformer. The equivalent circuit of the converter in this mode presented in Fig. $4 c$ is similar to that of the positive active state.

Taking into account that the qZS-network is symmetrical, we can assume that

$$
\begin{array}{ll}
L_{1}=L_{3}, & L_{2}=L_{4}, \\
C_{1}=C_{3}, & C_{2}=C_{4} .
\end{array}
$$

Correspondingly, the voltages are

$$
\begin{array}{ll}
v_{L 1}=v_{L 3}, & v_{L 2}=v_{L 4}, \\
V_{C 1}=V_{C 3}, & V_{C 2}=V_{C 4} .
\end{array}
$$

The sum of the capacitor voltages defines the peak value of the DC-link voltage:

$$
V_{D C}=V_{C 1}+V_{C 2}+V_{C 3}+V_{C 4},
$$

where $V_{C 1}, V_{C 2}, V_{C 3}, V_{C 4}$ are the average voltages across the capacitors over one switching period. At steady state the average voltage of the inductors over their operating period is zero and the dc voltages of the capacitors can be found from the voltage balance across the inductors:

$$
V_{C 1}=V_{C 3}=\frac{V_{I N}\left(1-D_{S}\right)}{2\left(1-2 \cdot D_{S}\right)}, \quad V_{C 2}=V_{C 4}=\frac{V_{I N} \cdot D_{S}}{2\left(1-2 D_{S}\right)} \text {. }
$$

The boost factor of the qZS network can be expressed as follows:

$$
B=\frac{V_{D C}}{V_{I N}}=\frac{V_{C 1}+V_{C 2}+V_{C 3}+V_{C 4}}{V_{I N}}=\frac{1}{1-2 \cdot D_{S}} .
$$

The gain factor of the proposed converter is expressed as follows:

$$
G=\frac{V_{O U T}}{V_{I N}}=\frac{n}{1-2 \cdot D_{S}},
$$

where $n$ is the turns ratio of the isolation transformer. 


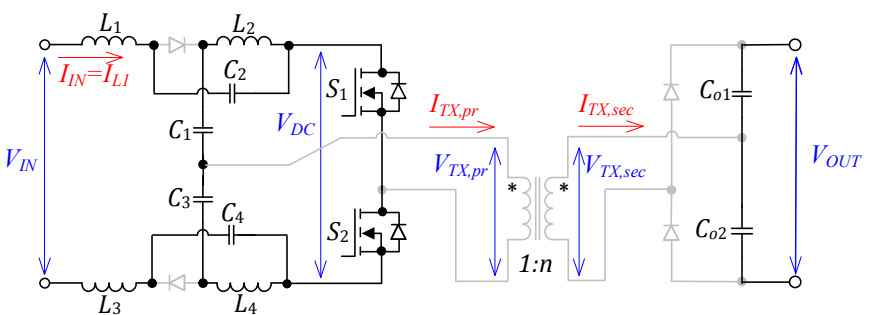

(a)

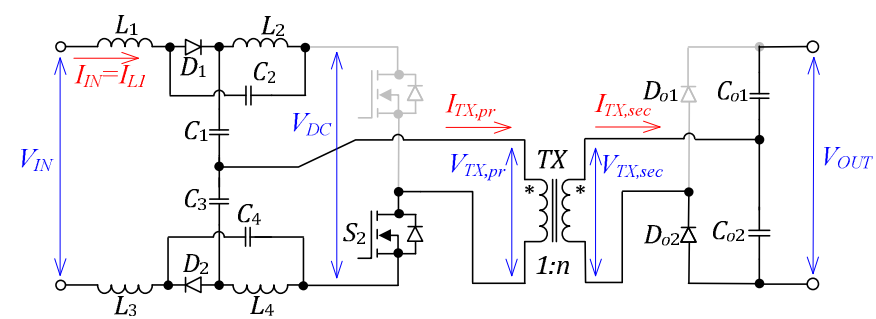

(b)

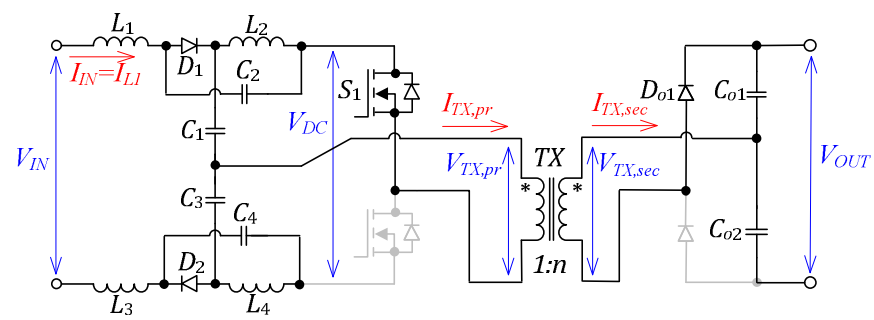

(c)

Fig. 4. Equivalent circuits of the proposed topology for its main operation states: shoot-through (a), positive active state (b) and negative active state (c).

\section{Component Stresses and General Design Guidelines}

The main purpose of the capacitors of the qZS network is to absorb the current ripple and limit the voltage ripple across the inverter. The voltage ripple across the capacitor can be roughly calculated by

$$
\Delta V_{C}=\frac{I_{L, a v} \cdot t_{S}}{2 \cdot C},
$$

where $I_{L, a v}$ is the average current through the qZS inductor, $C$ is the capacitance and $t_{S}$ is the total duration of the shootthrough states over the operating period. In the proposed topology the shoot-through time is evenly split into two intervals of half the duration (Fig. 3) and the qZS network operates with the frequency twice higher than the fundamental frequency of the isolation transformer. Assuming that $C_{1}=C_{3}$ the capacitance needed to limit the peak-to-peak voltage ripple by $K_{C}$ could be calculated as

$$
C_{1}=C_{3} \geq \frac{P \cdot D_{S} \cdot\left(1-2 D_{S(\max )}\right)}{f \cdot K_{C} \cdot V_{I N(\min )}^{2} \cdot\left(1-D_{S(\max )}\right)},
$$

where $P$ is the power rating of the converter, $f$ is the switching frequency, $V_{I N(\min )}$ is the minimum value of the input voltage, $D_{S(\max )}$ is the shoot-through duty cycle value corresponding to the minimum input voltage, and $K_{C}$ is the desired peak-to-peak voltage ripple across the capacitor $\left(K_{C}=\Delta V_{C} / V_{C}\right)$.

Capacitance values for capacitors $C_{2}$ and $C_{4}$ could be found similarly:

$$
C_{2}=C_{4} \geq \frac{P \cdot\left(1-2 D_{S(\max )}\right)}{f \cdot K_{C} \cdot V_{I N(\min )}^{2}} .
$$

The inductors in the qZS network will limit the current ripple through the switches during the shoot-through states. Peak-to-peak current ripple through the inductors can be calculated by

$$
\Delta I_{L 1}=\int_{0}^{\frac{T \cdot D_{S}}{2}} \frac{d I_{L 1}}{d t} \cdot d t=\int_{0}^{\frac{T \cdot D_{S}}{2}}\left(\frac{V_{I N}+V_{C 2}+V_{C 4}}{2 \cdot L}\right) \cdot d t .
$$

The average current through the inductors is equal to the average input current. In order to maintain the CCM operation of the converter, the input current ripple $\Delta I_{I N}$ should be smaller than the average input current $I_{I N}$. Therefore, the minimal inductance value of the qZS inductors where no discontinuous conduction mode (DCM) occurs is

$$
L \geq \frac{V_{I N(\min )}^{2} \cdot\left(1-D_{S(\max )}\right) \cdot D_{S(\max )}}{4 \cdot f \cdot\left(1-2 \cdot D_{S(\max )}\right) \cdot K_{L} \cdot P},
$$

where $K_{L}$ is the desired peak-to-peak input current ripple of the converter $\left(K_{L}=\Delta I_{I N} / I_{I N}\right)$.

To provide correct operation of the voltage doubler rectifier (VDR) and ensure the voltage doubling effect, the capacitors $C_{O 1}$ and $C_{O 2}$ (Fig. 2) should be properly dimensioned. In order to limit the peak-to-peak voltage ripple on these capacitors by $K_{C O}$, the capacitance of each capacitor should be

$$
C_{01}=C_{02} \geq \frac{P \cdot D_{S}}{2 \cdot f \cdot K_{C O} \cdot V_{O U T}^{2}} .
$$

The voltage and current stresses on the semiconductors for the ideal system are summarized in Table I.

TABLE I

VOLTAGE AND CURRENT STRESSES OF SEMICONDUCTORS

\begin{tabular}{|c|c|c|}
\hline Component & Maximum Voltage & Average Current \\
\hline $\begin{array}{c}\text { Diodes of the qZS } \\
\text { network }\left(D_{1}, D_{2}\right)\end{array}$ & $\frac{V_{\text {OUT }}}{2 \cdot n}$ & $\frac{P}{V_{I N}}$ \\
\hline $\begin{array}{c}\text { Transistors of the } \\
\text { half-bridge inverter } \\
\left(S_{1}, S_{2}\right)\end{array}$ & $\frac{V_{\text {OUT }}}{n}$ & $\frac{P}{V_{I N}}$ \\
\hline $\begin{array}{c}\text { Diodes of the voltage } \\
\text { doubler rectifier } \\
\left(D_{\mathrm{O} 1}, D_{\mathrm{O} 2}\right)\end{array}$ & $V_{\text {OUT }}$ & $\frac{P}{V_{\text {OUT }}}$ \\
\hline
\end{tabular}




\section{SiMULATION STUDY}

The proposed approach was validated by the computer simulations in the PSIM environment. In the qZS based topologies, the properties of semiconductors have direct impact on the step-up performance of the converter [9], therefore we used accurate models of the semiconductors based on the device datasheet values. To simplify the analysis, the ideal models of passive components (inductors, capacitors and isolation transformer) were used. The simulation parameters and generalized specifications of semiconductors are presented in Tables II and III, respectively. Two operating points corresponding to the maximum and minimum input voltages were studied. In both cases the average input current was kept at its maximum value $(5 \mathrm{~A})$. This approach is common for the PV oriented converters, because the PV panel behaves similarly to the current source with the limited output voltage. As shown in Fig. 4, the objects of our study were the input voltage boost properties, input current ripple, quality of the output voltage, and voltage stresses of the qZS capacitors.
TABLE II

SiMUlation PARAMETERS OF THE QZS HALF-BRIDGE DC-DC CONVERTER

\begin{tabular}{|c|c|c|}
\hline Parameter & Symbol & Value \\
\hline Input voltage range, $\mathrm{V}$ & $V_{I N}$ & $30 \ldots 58$ \\
\hline Maximum input current, $\mathrm{A}$ & $I_{I N}$ & 5 \\
\hline Output voltage, $\mathrm{V}$ & $V_{O U T}$ & 240 \\
\hline Switching frequency, $\mathrm{kHz}$ & $f_{s w}$ & 110 \\
\hline Operating frequency of qZS-network, $\mathrm{kHz}$ & $f_{q Z S}$ & $220\left(2 \cdot f_{s w}\right)$ \\
\hline Transformer turns ratio & $n$ & 4 \\
\hline Capacitance of qZS capacitors, $\mu \mathrm{F}$ & $C_{1} \ldots C_{4}$ & 26.4 \\
\hline Inductance of qZS inductors, $\mu \mathrm{H}$ & $L_{1} \ldots L_{4}$ & 24 \\
\hline Capacitance of output capacitors, $\mu \mathrm{F}$ & $C_{\mathrm{O} 1}, C_{\mathrm{O} 2}$ & 2.2 \\
\hline Converter power rating, $\mathrm{W}$ & $P$ & 300 \\
\hline
\end{tabular}

TABLE III

GENERAL SPECIFICATIONS OF SEMICONDUCTOR COMPONENTS USED IN SIMULATIONS AND EXPERIMENTS

\begin{tabular}{|c|c|c|}
\hline Component & Type & Specifications \\
\hline \multirow{2}{*}{$S_{1}, S_{2}$} & Infineon & $V_{D S}=250 \mathrm{~V} ; R_{D S(o n)}=60 \mathrm{~m} \Omega$ \\
& IPP600N25N3 & $I_{D}=25 \mathrm{~A}, Q_{g}=22 \mathrm{nC}, R_{g}=2.5 \Omega$ \\
\hline \multirow{2}{*}{$D_{1}, D_{2}$} & Vishay & $V_{R R M}=100 \mathrm{~V} ; V_{F}=0.66 \mathrm{~V}$ \\
& V60D100C & $I_{F(A V)}=2 \times 30 \mathrm{~A}($ common cathode) \\
\hline \multirow{2}{*}{$D_{\mathrm{o} 1, D_{\mathrm{o} 2}}$} & CREE & $V_{R R M}=600 \mathrm{~V} ; V_{F}=1.8 \mathrm{~V}$ \\
& C3D02060E & $I_{F(A V)}=4 \mathrm{~A}$ \\
\hline
\end{tabular}

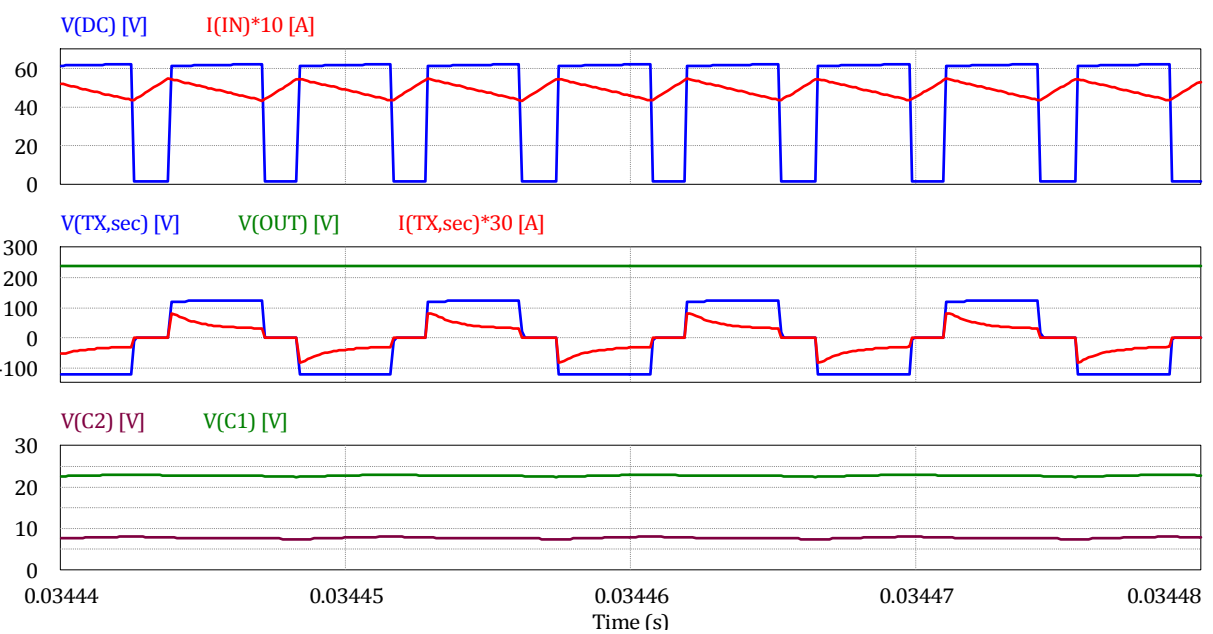

(a)

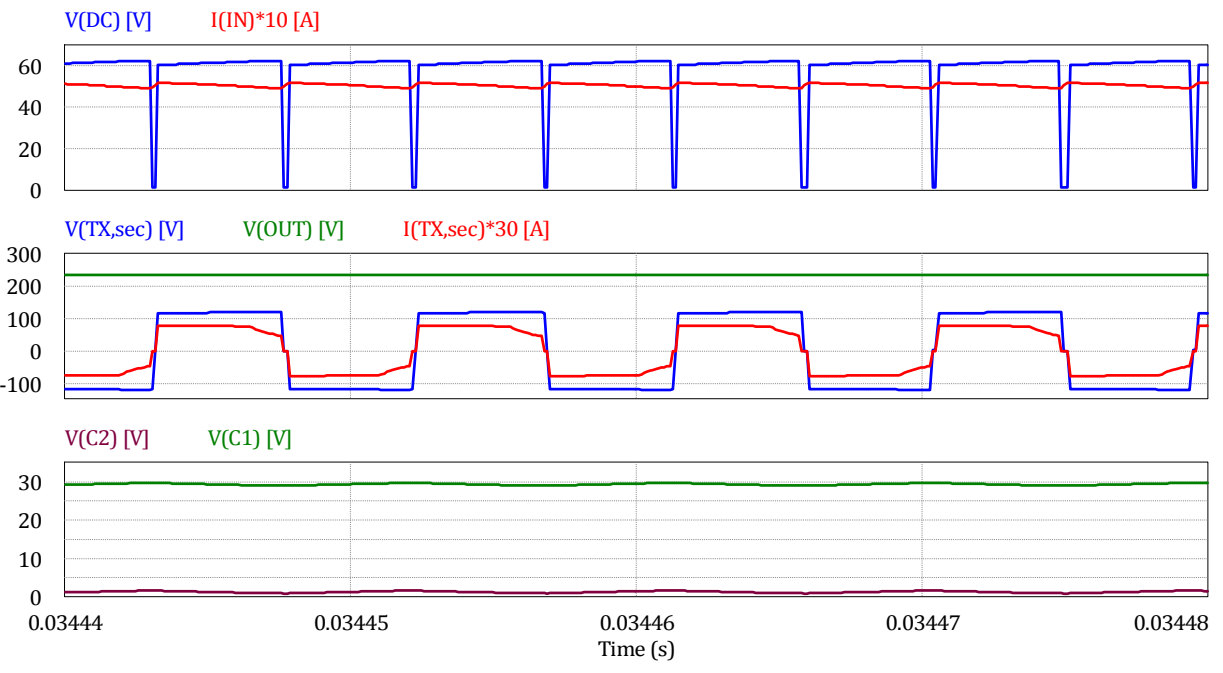

(b)

Fig. 4. Simulation results of the proposed topology at the minimum (a) and maximum (b) input voltages. 
In the first operating point with the input voltage of $30 \mathrm{~V}$, the shoot-through duty cycle was set to 0.27 to obtain the desired output voltage. Fig. $4 a$ shows that the qZS network ensures the demanded twofold gain of the input voltage $\left(V_{I N}=30 \mathrm{~V}\right.$ and $\left.V_{D C}=60 \mathrm{~V}\right)$ and continuous input current. As predicted by Eq. (6), the amplitude value of the $V_{D C}$ equals the sum of the capacitor voltages of the qZS network. Furthermore, the voltage doubler rectifier provides the demanded voltage doubling effect of the peak voltage of the secondary winding of the isolation transformer, thus ensuring the ripple-free output voltage of $240 \mathrm{~V}$ at the power close to $150 \mathrm{~W}$.

Next, the topology was tested with the maximum input voltage $(58 \mathrm{~V})$. The shoot-through duty cycle was reduced to 0.05 and the converter operated with the minimal input voltage boost factor ( $B$ close to 1 ). As shown in Fig. $4 b$, the operating voltage of the qZS capacitor $C_{2}$ (and, consequently, $C_{4}$ ) was decreased almost to zero, while the voltage of $C_{l}$ (and $C_{3}$ ) reached its maximum value. It was found that the converter was still maintaining the continuous input current, ensuring the ripple-free output voltage of $240 \mathrm{~V}$ at the rated power.

\section{EXPERIMENTAL RESULTS}

To verify the proposed topology experimentally, the $300 \mathrm{~W}$ prototype converter (Fig. 5) was assembled in accordance with the schematic in Fig. 2 and technical specifications in Table II.

Each qZS network contains the coupled inductor built on the EFD25 core made from N87 ferrite material with the resulting magnetizing inductance of $12 \mu \mathrm{H}$. The isolation transformer was wound on the ETD34; its magnetizing inductance was $30.8 \mu \mathrm{H}$ and leakage inductance referred to the primary was $0.35 \mu \mathrm{H}$. Chip monolithic ceramic capacitors SMD1210 $2.2 \mu \mathrm{F} 100 \mathrm{~V}$ from Murata were used to assemble the qZS network and the voltage doubler rectifier (12 units connected in series for each qZS capacitor and 9 units connected in $3 \times 3$ matrix configuration for the VDR capacitors). The types and generalized specifications of the semiconductors are presented in Table III. The prototype was built on the $250 \mathrm{~V} \mathrm{Si}$ MOSFETs, thus without optimization for the high efficiency.

The experimental setup was supplied from two PV simulators Agilent E4360A connected in series. Each PV

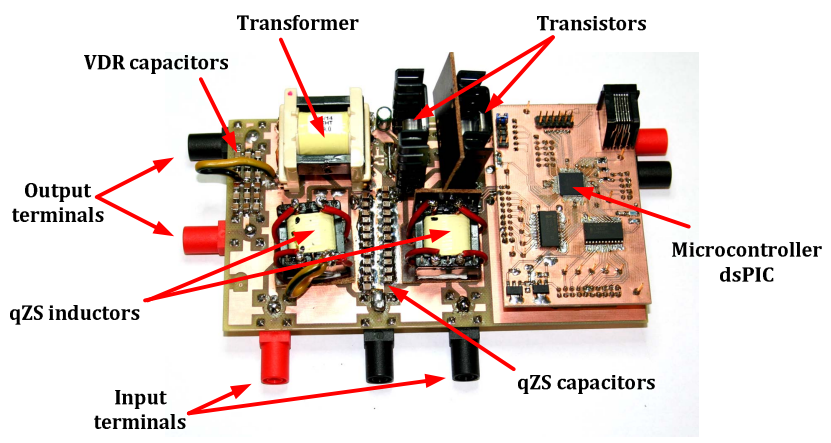

Fig. 5. Experimental prototype (165 mm x $90 \mathrm{~mm})$. simulator produced half of the input voltage of the converter, therefore the string connection of two PV panels was emulated.

Waveforms measured at the minimum input voltage $V_{I N}=30 \mathrm{~V}$ are shown in Fig. $6 a$. Shoot-through duty cycle near 0.3 was used to compensate the losses in the system and to achieve $240 \mathrm{~V}$ at the output terminals. Oscillations across transformer windings were observed during the shoot-through states, which is a common behavior of the half-bridge converters caused by the resonance between the transformer leakage inductance and the parasitic capacitance of the semiconductor components [10]. These voltage oscillations are reflected to the qZS diodes $D_{1}$ and $D_{2}$ that are reverse biased during the shoot-through states.

Waveforms measured at the maximum input voltage $V_{I N}=58 \mathrm{~V}$ are shown in Fig. $6 b$. Experimental results obtained somewhat differ from the simulation study (Fig. 4b) mainly due to the influence of the leakage inductance of the coupled inductors of the qZS networks and the leakage inductance of the transformer. High number of passive components leads to undesirable oscillations in the qZS network at the operation modes with a DC voltage gain close to unity. For example, these parasitic oscillations have been observed in the input current, as shown in Fig. $6 b$. In both cases the efficiency was limited by $92 \%$, which is mostly caused by the high on-state resistance of the MOSFETs.

\section{CONCLUSIONS AND FUTURE WORK}

In this paper the qZS half-bridge DC-DC converter was proposed as a new member of the impedance source galvanically isolated DC-DC converter family. To obtain the symmetrical structure, two identical qZS networks were mirror-connected. Each qZS network needs to handle half of the converter rated power. The topology could be used either with one or two input voltage sources. It has simple control due to reduced switch number and features the continuous input current in the CCM operation.

To validate the proposed topology, the experimental prototype with a rated power of $300 \mathrm{~W}$ was assembled and tested. Experimental results have verified all the theoretical assumptions. Voltage stresses of the capacitors and transistors all conformed to the theoretical predictions; however, waveforms of currents were influenced by the parasitic oscillations in the prototype. At the same time, the average values of the currents were not influenced.

Further research will be directed towards the analysis of the resonant processes within the converter and elaboration of the detailed design guidelines. In addition, the operation in the dual input mode with two input voltage sources connected through the common neutral node will be studied.

\section{ACKNOWLEDGMENT}

This research work was financed by Estonian Ministry of Education and Research (project SF0140016s11) and Latvian Council of Science (Grant 416/2012). 

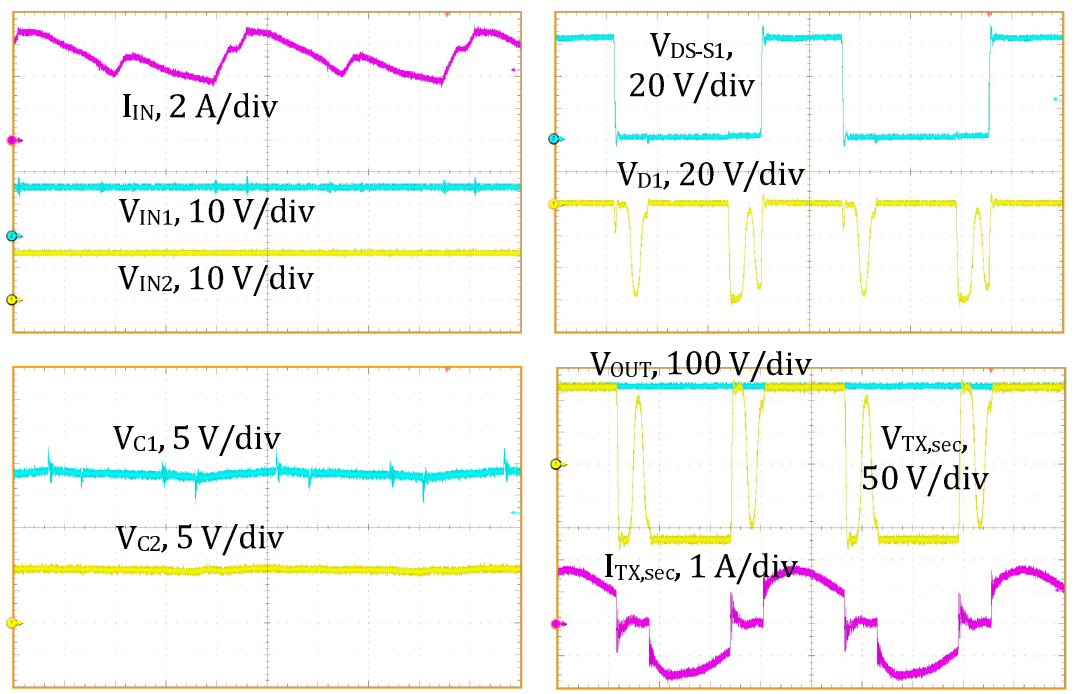

(a)
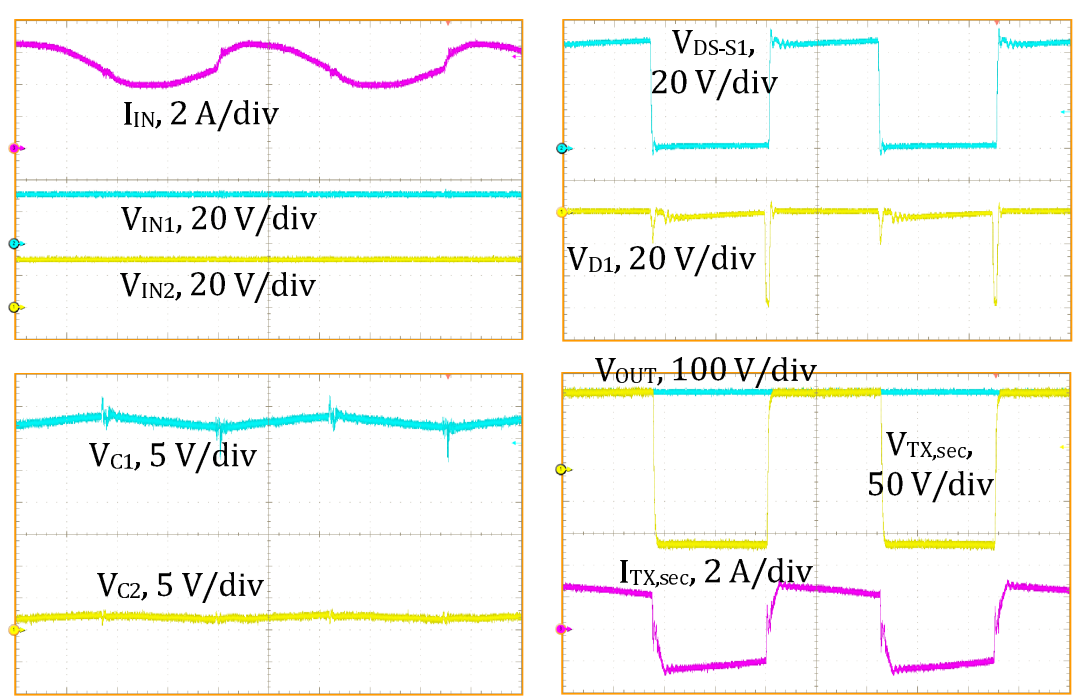

(b)

Fig. 6. Experimental results of the proposed topology at the minimum (a) and maximum (b) input voltages.

This research was supported by European Social Fund's Doctoral Studies and Internationalisation Programme DoRa, which is carried out by Foundation Archimedes.

\section{REFERENCES}

[1] D. Vinnikov, I. Roasto, and T. Jalakas, "New step-up DC-DC converter with high-frequency isolation," in Proc. 35th Annu. Conf. of IEEE Ind. Electron. Soc. (IECON), 3-5 Nov. 2009, pp. 670675.

[2] M. Egorov, D. Vinnikov, R. Strzelecki, and M. Adamowicz, "Impedance source inverter based high-power DC-DC converter for fuel cell applications," in Proc. of 8th EEEIC Int. Conf. on Environment and Elect. Eng., 10-13 May 2009, pp. 1-4.

[3] D. Vinnikov, and I. Roasto, "Quasi-Z-source-based isolated DC-DC converters for distributed power generation," IEEE Trans. Ind. Electron., vol. 58, no. 1, pp. 192-201, Jan. 2011.

[4] M.-K. Nguyen, Q.-D. Phan, V.-N. Nguyen, Y.-C. Lim, and J.-K. Park, "Trans-Z-source-based isolated DC-DC converters," in Proc. IEEE 22nd Int. Symp. on Ind. Electron. (ISIE), 28-31 May 2013, pp. 16

[5] Y. P. Siwakoti, P. C. Loh, F. Blaabjerg, and G. E. Town, "Magnetically coupled high-gain Y-source isolated DC-DC converter," IET Power Electronics, vol. 7, no. 11, pp. 2817-2824, Nov. 2014.
[6] A. Chub, O. Husev, D. Vinnikov, and F. Blaabjerg, "Novel family of quasi-Z-source DC-DC converters derived from current-fed push-pull converters," in Proc. 16th Conf. on Power Electron. and Applicat. (EPEECCE Europe), 26-28 August 2014, pp. 1-10.

[7] Y. P. Siwakoti, F. Blaabjerg, P. C. Loh, and G. E. Town, "High-voltage boost quasi-Z-source isolated DC-DC converter," IET Power Electron., vol. 7, no. 9, pp. 2387-2395, Sept. 2014.

[8] I. Roasto, D. Vinnikov, T. Jalakas, J. Zakis, S. Ott, "Experimental study of shoot-through control methods for qZSI-based DC/DC converters," in Proc. Power Electronics Electrical Drives Automation and Motion (SPEEDAM), pp.29,-34, 14-16 June 2010.

[9] D. Vinnikov, I. Roasto, "Impact of component losses on the voltage boost properties and efficiency of the qZS-converter family," in Proc. 7th International Conference-Workshop Compatibility and Power Electronics (CPE), pp.303-308, 1-3 June 2011.

[10] A. Blinov, T. Jalakas, D. Vinnikov, K. Janson, "Switch-Off Behaviour of $6.5 \mathrm{kV}$ IGBT Modules in Two-Level Voltage Source Inverter". Scientific Journal of Riga Techical University: Power and Electrical Engineering, vol. 27, pp. 121-126, 2010. 